\title{
CD19 and CD22 Regulate a B Lymphocyte Signal Transduction Pathway That Contributes to Autoimmunity
}

\author{
Thomas F. Tedder, Shinichi Sato, Jonathan C. Poe and Manabu Fujimoto \\ Department of Immunology, Duke University Medical Center, Durham, NC, USA
}

(Received for publication on December 6, 1999)

\begin{abstract}
The fate of B lymphocytes is dependent on intrinsic and B cell antigen receptor (BCR)induced signals. These signals are modified and interpreted by other cell-surface molecules such as CD19 and CD22 that govern mature $B$ cell activation. This review assesses our current understanding of how CD19 and CD22 regulate B lymphocyte signaling and how alterations in these response-regulators contribute to autoimmunity in mice and humans. We propose that CD19 functions as a specialized adapter protein that regulates B lymphocyte signaling and autoantibody production. Overexpression of CD19 by B cells in systemic sclerosis patients correlates with autoantibody production and transgenic mice that overexpress CD19 produce similar autoantibodies. CD19 establishes a novel Src-family kinase activation loop that regulates basal signal transduction thresholds in resting $B$ cells and amplifies Src-family kinase activation following BCR ligation. Reciprocally, CD22 is a potent regulator of CD19 function. These observations provide insight into how $\mathrm{CD} 19$ and $\mathrm{CD} 22$ govern the molecular ordering and intensity of signals transduced in B cells that may contribute to autoimmunity. (Keio J Med 49 (1): 1-13, March 2000)
\end{abstract}

Key words: B lymphocyte, autoimmunity, CD19, CD22, signal transduction

\section{Introduction}

The fate of B lymphocytes is dependent on basal and $B$ cell antigen receptor (BCR)-induced signals. The BCR complex is comprised of membrane immunoglobulin (Ig) noncovalently associated with disulfide-liked $\mathrm{CD} 79 \mathrm{a} / \mathrm{CD} 79 \mathrm{~b}(\operatorname{Ig} \alpha / \operatorname{Ig} \beta)$ heterodimers. Membrane $\mathrm{Ig}$ mediates ligand binding, while CD79 $\mathrm{a}$ and $\mathrm{CD} 79 \mathrm{~b}$ contain immunoreceptor tyrosine-based activation motif (ITAM) sequences that function as signal transducing elements. BCR engagement activates signaling pathways through two distinct classes of non-receptor protein tyrosine kinases (PTKs) including Syk and the Srcfamily members, Lyn, Fyn, Blk, and Lck. ${ }^{1-4}$ Src-family PTKs associate with the BCR complex in resting B cells and become activated upon BCR ligation. ${ }^{5}$ Activated Src-family PTKs, primarily Lyn, phosphorylate tyrosine residues within ITAMs of CD79a/CD79b, which results in the recruitment of Syk through its Src homology 2 (SH2) domains. ${ }^{6}$
Lyn, the predominant Src-family member in B cells, has a crucial initiating role in BCR signaling. However, Lyn is also essential for feedback regulation since it phosphorylates immunoreceptor tyrosine-based inhibitory motifs (ITIM) within negative regulatory molecules. ${ }^{5.7-10}$ In addition, regulation of Src-family PTK's catalytic activity is mediated by phosphorylation of two different tyrosine residues, which reciprocally regulate kinase activity. ${ }^{11,12}$ PTK function is also regulated by "cross-talk" between PTKs, protein tyrosine phosphatases, and interactions with intracellular regulatory and adapter proteins. ${ }^{13.14}$ PTK activation in turn propagates multiple downstream signaling events including tyrosine phosphorylation of important transmembrane receptors, phosphoinositide turnover and intracellular calcium $\left(\left[\mathrm{Ca}^{++}\right]_{\mathrm{i}}\right)$ increases through the activation of phospholipase C- $\gamma 2$ (PLC- $\gamma 2$ ). PTK activity also influences the activation of mitogen-activated protein kinases (MAPKs), including the extracellular signalregulated kinase (ERK), c-jun $\mathrm{N}$-terminal kinase

Presented at the 1137th Meeting of The Keio Medical Society in Tokyo, October 15, 1999.

Reprint requests to: Dr. Thomas F. Tedder, Department of Immunology, Duke University Medical Center, Box 3010, Durham, NC 27710, USA, e-mail: thomas.tedder@duke.edu

This work was supported by grants from the National Institutes of Health, USA; CA81776 and CA54464. 
(JNK), and p38.

Intrinsic and BCR-induced signals are also regulated by $\mathrm{B}$ lymphocyte cell-surface molecules that modify and provide a context for BCR signal transduction. ${ }^{15}$ These cell-surface molecules are commonly called "costimulatory molecules" when they function in conjunction with the BCR to amplify signal transduction. However, another class of cell surface molecules are the "response-regulators" of lymphocyte signaling. ${ }^{15}$ Response-regulators carry out broader functions than costimulatory molecules since they establish intrinsic signaling thresholds that provide a context for transmembrane signals including BCR-generated signals. We have recently suggested that CD19 and CD22 are members of the response-regulator class of cell-surface molecules. ${ }^{16,17}$ CD19 and CD22 may each reciprocally regulate BCR signaling by associating directly with cellsurface IgM. ${ }^{18-20}$ Herein this review, we propose a unique molecular mechanism through which tyrosine phosphorylated CD19 and CD22 function cooperatively to regulate a Src-family PTK activation loop that modulates intrinsic and BCR-induced signals. ${ }^{21}$ These findings provide a mechanistic explanation of how CD19 regulates basal signaling thresholds and accelerates BCR signaling in vivo. Increased activity of this CD19/ Src family kinase amplification loop may explain why patients and mice that overexpress CD19 are predisposed to produce autoantibodies.

\section{CD19 and CD22 Expression Influence Autoimmunity}

The production of autoantibodies is regulated by self-antigens signaling through $\mathrm{B}$ cell antigen receptors. These responses are further influenced by CD19, CD22 and other signal transduction molecules that function as response regulators to amplify or inhibit BCR signaling. ${ }^{22}$ Intracellular regulatory molecules that appear to control BCR signaling intensity also include Lyn, Btk, Vav, and the SHP1 protein tyrosine phosphatase. ${ }^{9,22,23}$ Recently, we have demonstrated that CD19, CD21, CD22, Lyn, Vav, and SHP1 are functionally linked in a common signaling pathway.

Remarkably, mice with altered CD19, CD21, CD22, Lyn or SHP1 expression produce autoantibodies and develop autoimmunity to varying degrees. Peripheral tolerance is disrupted in mice that overexpress CD19, which results in the spontaneous production of IgG subclass autoantibodies. ${ }^{24.25}$ Self-reactive B cells deficient in CD21 expression are not anergized by soluble self-antigen in mouse models of tolerance. ${ }^{26} \mathrm{CD} 22 \mathrm{de}$ ficiency is sufficient to predispose to development of high affinity autoantibodies in mice. ${ }^{27}$ Lyn-deficient mice exhibit glomerulonephritis due to the presence of immune complexes containing autoantibodies. ${ }^{28,29}$ Motheaten viable mice which bear SHP1 mutations demonstrate elevated levels of spontaneous autoantibodies, hypergammaglobulinemia, and tissue deposition of immune complexes. ${ }^{30}$ Thus, each of these responseregulators for $\mathrm{BCR}$ signaling are suggested to play a critical role in autoantibody production. ${ }^{22}$

Although multiple molecules involved in a common CD19 signal transduction pathway influence autoimmunity in mice, similar examples in humans have only recently become available. Systemic sclerosis (SSc) is a multisystem disorder of connective tissue characterized by sclerotic changes in the skin and internal organs. Autoantibodies are detected in more than $90 \%$ of SSc patients and are considered to play a critical role in the pathogenesis of SSc. ${ }^{31}$ In a recent study, we found that CD19 and CD21 expression levels were $20 \%$ higher on B cells from SSc patients compared with healthy individuals, while CD20, CD22, and CD40 expression were normal (Sato S, Hasegawa M, Tedder TF, Takehara K: Quantitative genetic variation in CD19 expression correlates with autoimmunity, manuscript submitted). Evidence that a $20 \%$ increase in CD19 expressed induces the autoantibodies found in SSc was obtained using transgenic mice that overexpress CD19 to a similar extent. Like in SSc patients, CD19 overexpression by $20 \%$ induced autoantibody production in a normally nonautoimmune strain of mice. Antinuclear antibodies, especially anti-spindle pole antibodies, as well as antisingle-stranded DNA, anti-double-stranded DNA and anti-histone antibodies, and rheumatoid factor were induced in these mice, but not wild type littermate controls. Thus, modest alterations in CD19 function or expression could contribute to the development of autoantibodies in humans. Moreover, similar subtle alterations in the expression or function of other regulatory molecules involved in the CD19 signal transduction pathway may also predetermine autoimmunity susceptibility in other autoimmune syndromes. Although speculation, it is possible that graded alterations in expression or function in these "response-regulators" may result in the spectra of autoantibody specificities characteristic of the different autoimmune diseases.

\section{CD19}

\section{CD19 expression, structure and function}

CD19 is a $\sim 95 \mathrm{kDa}$ B lymphocyte-specific cellsurface glycoprotein of the Ig superfamily expressed by early pre-B cells until plasma cell differentiation. ${ }^{24,32}$ CD19 density on the cell surface is highly regulated during development with similar expression levels by all mature conventional B cells from different peripheral lymphoid tissues. ${ }^{32,33}$ Cellular activation induced by anti-IgM antibodies, lipopolysaccharide (LPS) and IL-4 does not alter CD19 expression in either mice or 
humans. ${ }^{32,34}$ Thus, CD19 expression appears to be tightly controlled.

CD19 is part of a multimolecular complex (Fig. 1) that involves various intracellular signaling pathways. ${ }^{17}$ When expressed on the cell surface, CD19 interacts non-covalently with cell-surface $\mathrm{CD} 21$, a receptor for complement clevage fragments generated during complement activation. ${ }^{35}$ In addition, CD19 interacts with CD81, a broadly expressed member of the tetraspans family of cell-surface molecules that are involved in multiple diverse signaling pathways. ${ }^{36,37}$ Recently, CD81-deficient mice have revealed that CD81 expression is important for optimal cell-surface CD19 expression. The major hallmark of CD81-deficiency is decreased CD19 expression and signaling in B cells. ${ }^{38-40}$ CD81 associates with another widelyexpressed cell-surface molecule termed Leu-13. ${ }^{41-43}$ Although the functional significance of this multimolecular complex on the cell surface is not understood, it is envisioned that CD19 and its associated CD81/Leu-13 molecules provide a signaling function for informing $B$ cells of complement activation in the microenvironment.
Two different models for CD19 complex function/ signaling have been proposed (Fig. 2). CD19 can function as a costimulatory molecule for the augmentation of $\mathrm{B}$ cell proliferation in vitro. ${ }^{22.44}$ This has led to the suggestion that the $\mathrm{CD} 21 / \mathrm{CD} 19$ complex serves as a costimulatory molecule for BCR signals when C3d fragments covalently bound to antigen coligates the CD21/CD19 complex with the BCR. ${ }^{45}$ In this context, CD19 and BCR signaling would be upregulated when antigen-specific $B$ cells encounter antigen-C3d complexes in vivo.

CD19 also functions as an intrinsic responseregulator, ${ }^{22}$ as revealed in studies of mice that lack or overexpress CD19. ${ }^{46-48}$ Changing CD19 expression levels in gene-targeted or transgenic mice significantly alters peripheral $B$ cell numbers and their function. In CD19-deficient mice, B cells develop normally, but fail to expand in the periphery and spleen. CD19-deficient $\mathrm{B}$ cells are hypo-responsive to most transmembrane signals, including BCR ligation and mitogens, which leads to significant deficiencies in proliferation, clonal expansion and differentiation. ${ }^{24,32,46,49,50}$ Although CD19-deficient $B$ cells express cytoplasmic signal-

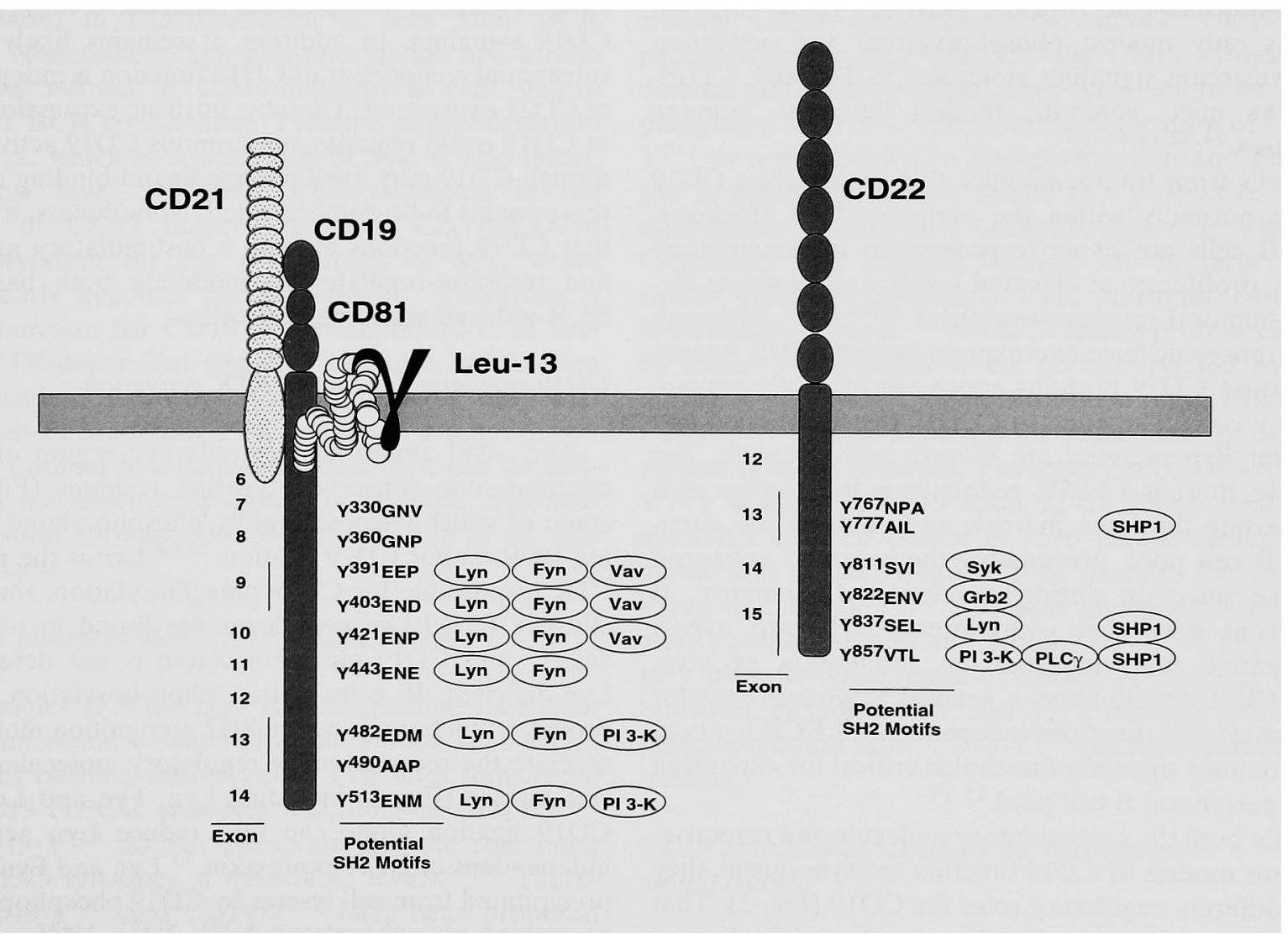

Fig. 1 Model of CD19 and CD22 structure (shaded) and associations with other signaling molecules. Y designates sites of potential tyrosine phosphorylation in the cytoplasmic domains of human CD19 and CD22. Amino acid positions are as described. ${ }^{22,70}$ 


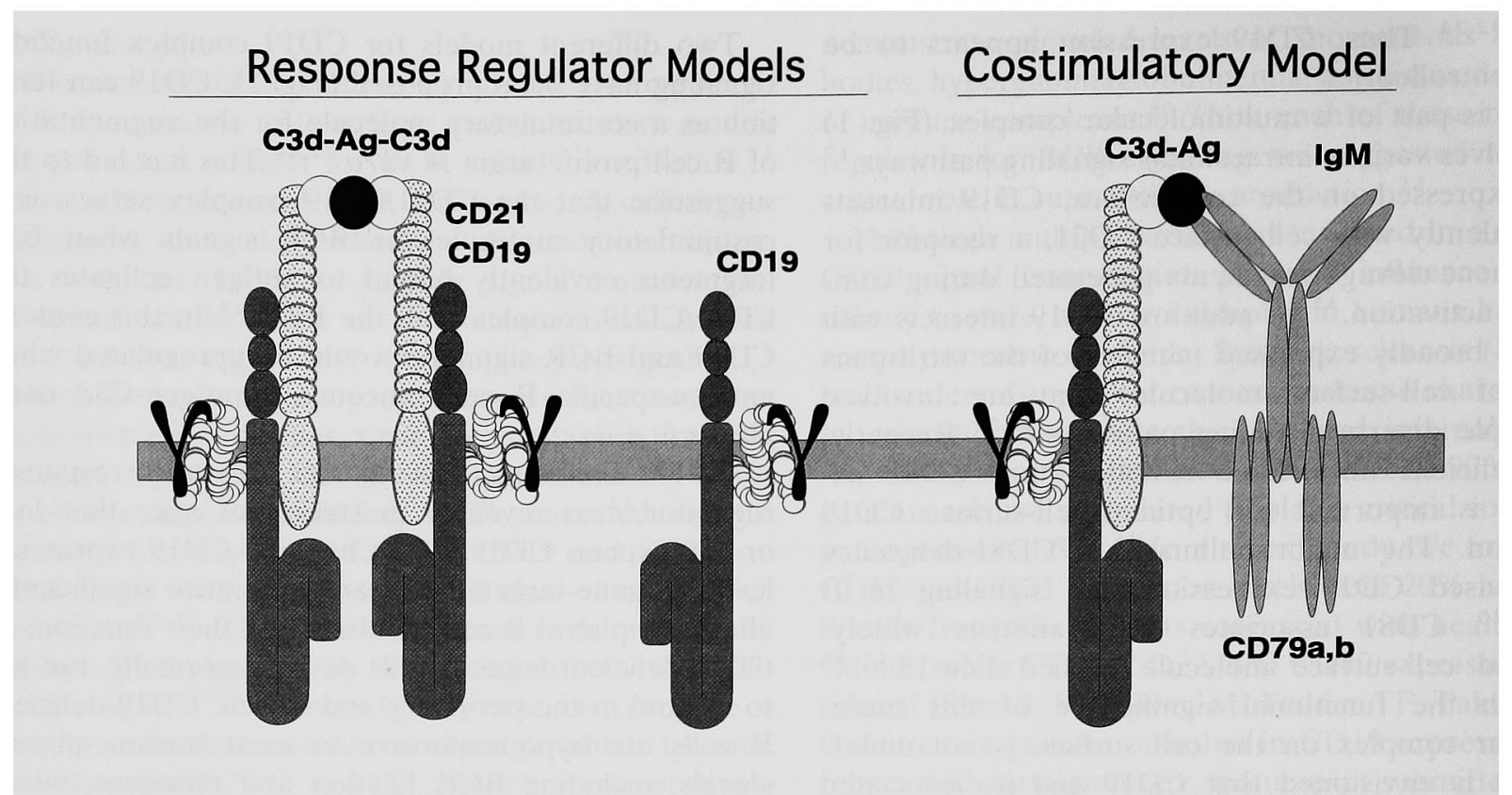

Fig. 2 Models for CD19 function in vivo. CD21 associated with CD19 binds antigen complexes covalently modified with the $\mathrm{C} 3 \mathrm{~d}$ fragment of complement (C3d-Ag-C3d). In the costimulatory model, Ag-C3d complexes crosslink Agspecific BCRs and $\mathrm{CD} 19$ by engaging both $\mathrm{CD} 21$ and the BCR.

ing molecules at normal levels, BCR ligation induces only modest phosphorylation and activation of downstream signaling molecules. ${ }^{21}$ Thereby, CD19deficient mice generate modest humoral immune responses. $^{24,32,46,48-50}$

B cells from transgenic mice that overexpress CD19 mature normally within the periphery. ${ }^{46,47}$ However, these B cells are hyper-responsive to transmembrane signals, proliferate at elevated levels, and generate elevated humoral immune responses. ${ }^{24,32,49,50}$ Although these transgenic mice overexpress human CD19, human and mouse CD19 proteins appear functionally equivalent in vivo. ${ }^{32}$ The effects of CD19 overexpression and resultant hyperactivity are diverse and dramatic. For example, there is a $>95 \%$ reduction in the number of $B$ cells exiting the bone marrow and entering the circulating B cell pool, presumably the result of enhanced negative selection during development. Similarly, B cells from mice that overexpress CD19 are hyperproliferative following mitogen stimulation ex vivo. Thus, CD19 functions as a general response-regulator or rheostat that functions independent of BCR ligation, which defines signaling thresholds critical for expansion of the peripheral B cell pool. ${ }^{15,17}$

While both the costimulatory molecule and responseregulator models of CD19 function are synergistic, they imply different regulatory roles for CD19 (Fig. 2). That the majority of mature $B$ cells are affected by loss or overexpression of CD19 suggests that CD19 regulates $B$ cell function independent of $\mathrm{BCR}$ engagement, but antigen-induced complement activation may activate CD19 signaling. In addition, it remains likely that a substantial component of CD19 function is independent of CD21 expression. Thereby, intrinsic expression levels of CD19 could regulate autonomous CD19 activity. Although CD19 may itself possess ligand-binding activity, this remains to be demonstrated. Nonetheless, it is clear that CD19 functions as both a costimulatory molecule and response-regulator to modulate both basal and BCR-induced signaling in B cells.

\section{CD19 regulates Src-family PTK activation}

The $\sim 240$ amino acid cytoplasmic region of CD19 contains nine conserved tyrosine residues (Fig. 1), ${ }^{51}$ some of which become rapidly phosphorylated following BCR and/or CD19 ligation. ${ }^{22,44}$ Lyn is the primary PTK responsible for CD19 phosphorylation, since constitutive CD19/Lyn complexes are found in resting B cells, ${ }^{21}$ and CD19 phosphorylation is not detected in Lyn-deficient B cells. After phosphorylation, CD19 provides functionally active $\mathrm{SH} 2$ recognition motifs that mediate the recruitment of regulatory molecules to the cell surface (Fig. 1) including Lyn, Fyn and Lck. ${ }^{52-54}$ CD19 ligation alone can also induce Lyn activation independent of BCR expression. ${ }^{53}$ Lyn and Fyn can be precipitated from cell lysates by CD19 phosphopeptides containing phosphorylated $\mathrm{Y}^{391}, \mathrm{Y}^{421}, \mathrm{Y}^{482}$, or $\mathrm{Y}^{513}$, and weakly using $\mathrm{Y}^{403}$ and $\mathrm{Y}^{443}$ phosphopeptides (Fig. 1). By contrast, Syk and Btk do not interact with CD19 
phosphopeptides or intact protein at detectable levels, suggesting that phosphorylated CD19 interacts specifically with Src-family PTKs.

While Lyn is required for CD19 phosphorylation, the reverse is also true. Overall tyrosine phosphorylation of cellular proteins is dramatically decreased in CD19deficient B cells before and after BCR ligation. ${ }^{21}$ Lyn, Fyn, Blk, and Lck phosphorylation increase modestly in CD19-deficient B cells following BCR crosslinking, although CD19-deficient B cells express these Src-family PTKs at wild type levels. Altered maturation does not explain this observation since CD19-deficient B cells develop normally and express wild type levels of Fgr which is predominantly expressed by mature B cells. ${ }^{55}$ $B$ cells from mice that overexpress CD19 mature normally and express Lyn protein at wild type levels. ${ }^{32,46}$ However, Lyn kinase activity is increased in B cells from transgenic mice that overexpress CD19. ${ }^{56}$ Analogously, CD19 expression by a plasmacytoma cell line enhances Lyn tyrosine phosphorylation when compared with parental CD19-negative cells. ${ }^{57}$ These studies collectively demonstrate that CD19 expression regulates Src-family PTK activity.

Consistent with decreased tyrosine phosphorylation of the Src-family PTKs, CD79a/CD79b phosphorylation is decreased in CD19-deficient B cells after BCR ligation. Nonetheless, Syk phosphorylation and kinase activity is normal in CD19-deficient $B$ cells before and after BCR crosslinking. Tyrosine phosphorylation of PLC- $\gamma 2$, which is downstream of Syk, is also intact. Thus, low level Src-family PTK activation in the absence of CD19 induces sufficient CD79a/CD79b phosphorylation for the recruitment of Syk, which subsequently becomes phosphorylated. ${ }^{1}$ Therefore, a critical function for CD19 is the amplification of Srcfamily PTK-dependent signaling cascades, rather than Syk-dependent pathways. Consistent with this, wild type levels of Src-family PTK activation are not necessary for optimal Syk activation since Syk can be activated in the absence of Lyn. ${ }^{58}$ In addition, Syk selfamplification through autophosphorylation is an efficient process. ${ }^{59}$

\section{Tyrosine phosphorylation sites within CD19}

Although CD19 has nine tyrosine residues, the location of functional tyrosine phosphorylation sites within CD19 has become controversial. Cell lines transfected with CD19 cDNAs encoding mutations of CD19-Y ${ }^{482}$ and $C D 19-Y^{513}$ do not phosphorylate the remaining seven CD19 tyrosines at detectable levels. ${ }^{60,61}$ Therefore, CD19-Y ${ }^{482}$ and CD19-Y ${ }^{513}$ have been proposed to be the only phosphorylated tyrosines within CD19. However, CD19 functions as a transmembrane adapter protein for the recruitment of Vav to phosphorylated
CD19-Y ${ }^{391}$, a primary binding site for Vav ${ }^{62-64}$ Vav also binds other phosphotyrosines within the CD19 cytoplasmic domain at lower levels. ${ }^{56} \mathrm{CD} 19-\mathrm{Y}^{391}$ phosphorylation has physiological relevance since CD19 expression is required for optimal Vav phosphorylation, ${ }^{65}$ and mutation of $\mathrm{CD} 19-\mathrm{Y}^{391}$ results in impaired activation of MAPKs. ${ }^{63}$ Therefore, CD19$\mathrm{Y}^{482}$ and $C D 19-\mathrm{Y}^{513}$ are unlikely to be the only phosphorylated tyrosines in CD19.

In vitro studies examining tyrosine phosphorylation sites within recombinant $C D 19$ have offered an explanation for the paradox outlined above. ${ }^{56}$ These studies demonstrate that CD19 has two preferential Lyn phosphorylation sites when presented as peptides: $\mathrm{Y}^{391}$ and $\mathrm{Y}^{513}$, although other residues are phosphorylated at lower levels. However, the phosphorylation pattern is different for an intact CD19 cytoplasmic domain. We therefore propose that the CD19 cytoplasmic domain is highly folded due to its multiple highly-charged regions. ${ }^{66}$ In its folded state, CD19- $\mathrm{Y}^{513}$ is likely to be the preferential Lyn phosphorylation site following BCR engagement and Lyn activation (Fig. 3A,B), and then phosphorylated $\mathrm{Y}^{513}$ acts as a nucleation site to retain Lyn through its $\mathrm{SH} 2$ domain (Fig. 3B). Phosphorylated CD19-Y ${ }^{513}$ is the preferred Lyn binding site among CD19 phosphotyrosine motifs. CD19-Y ${ }^{513}$ phosphorylation may "unfold" the CD19 cytoplasmic domain and thereby allow other tyrosines to be phosphorylated (Fig. 3C). The C-terminal location of CD19$\mathrm{Y}^{513}$ as a preferred Lyn phosphorylation and binding site is consistent with a model of "processive phosphorylation". Processive phosphorylation is where a C-terminal SH2 domain binding site in target substrates enhances Src-family PTK phosphorylation of $\mathrm{N}$-terminal tyrosines. ${ }^{67}$ A CD19 fusion protein lacking an intact $\mathrm{Y}^{513}$ residue is not phosphorylated by Lyn during in vitro assays, demonstrating a requirement for CD19-Y ${ }^{513}$ phosphorylation for subsequent phosphorylation of other residues. Phosphorylation of a CD19$\mathrm{Y}^{482} \mathrm{~F}$ mutant of $\mathrm{CD} 19$ exon $12-14$ fusion protein is markedly reduced during in vitro kinase assays compared with an intact exon 12-14 protein, further verifying that $\mathrm{CD} 19-\mathrm{Y}^{\mathbf{4 8 2}}$ is a Lyn phosphorylation site after phosphorylation and binding to $\mathrm{Y}^{513}$. Thus, Lyn may phosphorylate more proximal N-terminal CD19 tyrosines, including $\mathrm{Y}^{482}$ and $\mathrm{Y}^{391}$, through processive phosphorylation after CD19- $Y^{513}$ phosphorylation and binding.

\section{CD19 amplifies Lyn activity by "processive amplification"}

The recent finding that Lyn interactions with CD19 directly amplify Lyn activation provides a new understanding of CD19 function and explains many of the 


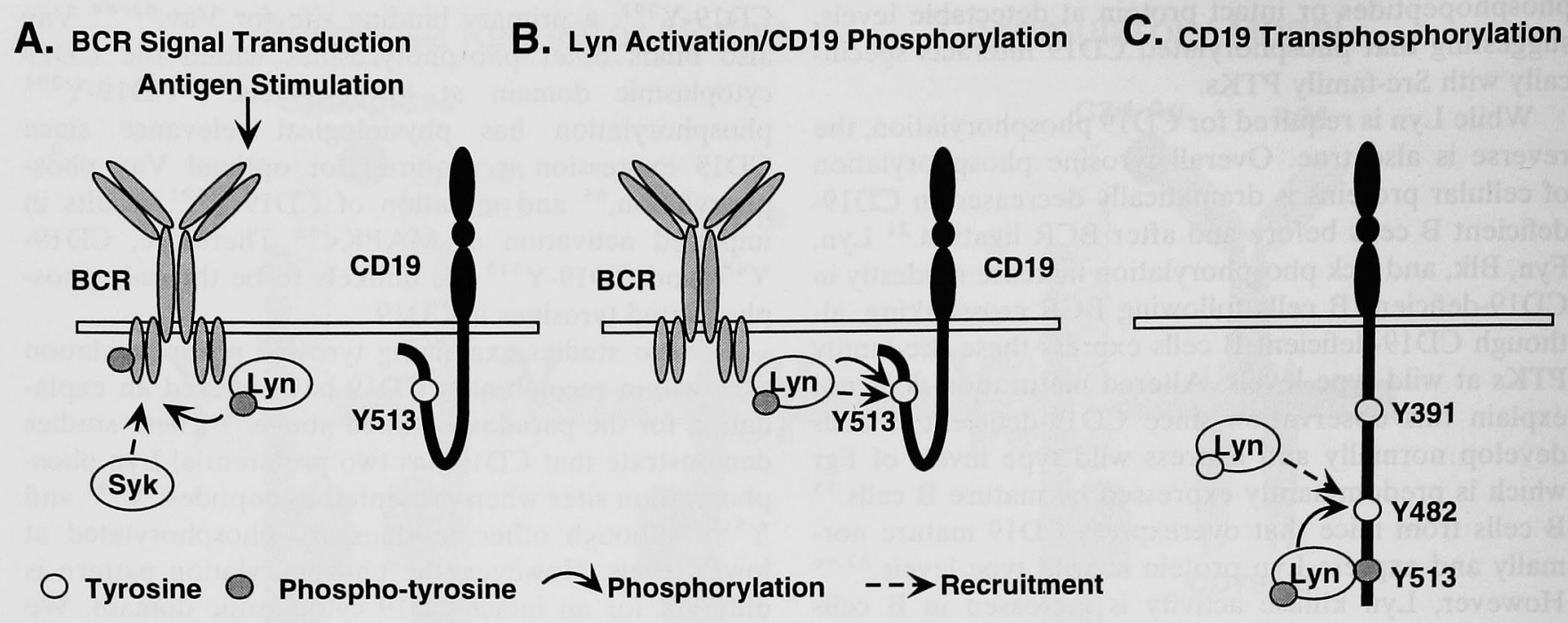

D. Kinase Amplification Loop

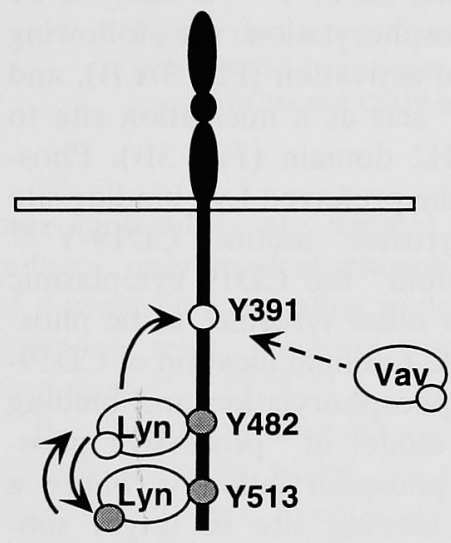

E. Vav Activation

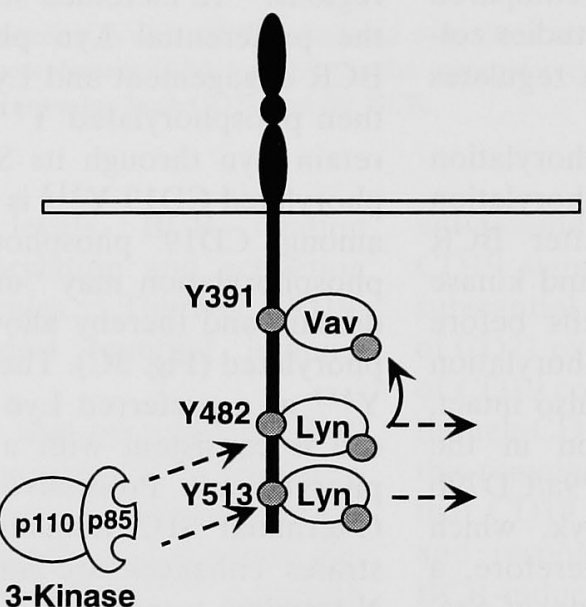

F. CD22 Phosphorylation / SHP1 Recruitment

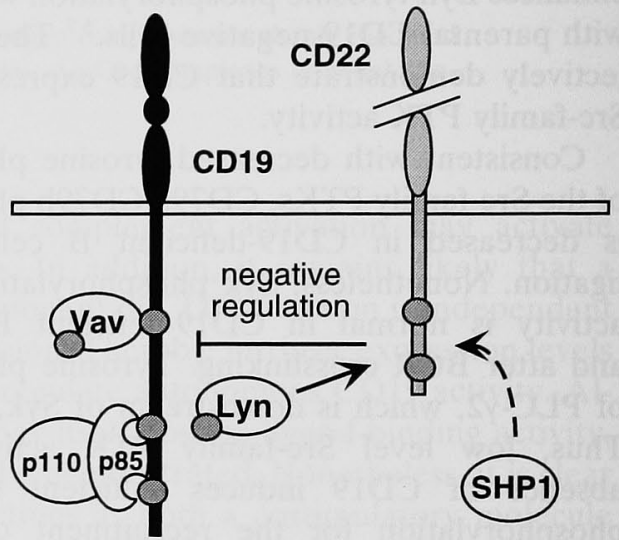

Fig. 3 A potential model for CD19 "processive amplification" of Lyn activity. ${ }^{56}$ (A) Following BCR cross-linking, Lyn and other Src-family PTKs become activated. Lyn then phosphorylates tyrosines within the ITAMs of CD79a and CD79b. Syk is then recruited to tandem phosphotyrosines and becomes activated. (B) Following BCR and/or CD19 cross-linking, Lyn phosphorylates exposed CD19- $\mathrm{Y}^{513}$. (C) Lyn then binds phosphorylated CD19- $\mathrm{Y}^{513}$ via its $\mathrm{SH} 2$ domain, and phosphorylates $\mathrm{CD} 19-\mathrm{Y}^{+82}$ through "processive phosphorylation". Following phosphorylation, the closed structure of the CD19 cytoplasmic domain is relaxed, exposing other potential sites for phosphorylation. (D) Phosphorylated CD19- $\mathrm{Y}^{482}$ recruits another Lyn molecule, which leads to Lyn transphosphorylation and/or autophosphorylation and the formation of a Src-family PTK amplification loop. This leads to phosphorylation of CD19-Y ${ }^{391}$ and Vav recruitment. (E) Vav may then be phosphorylated by activated Lyn, leading to the activation of downstream signaling pathways and MAPK activation. Once activated, Lyn may lose its SH2 domain-binding affinity and release CD19, thereby allowing the recruitment of unactivated Lyn into the CD19-mediated Src-family PTK amplification loop. Additionally, Lyn release from CD19 may allow the tandem SH2 domains of PI 3-kinase to interact with CD19-Y ${ }^{482}$ and CD19-Y ${ }^{513}$. (F) CD19 amplification of Src-family PTK activation (most likely Lyn) leads to optimal CD22 phosphorylation. Tyrosine phosphorylated CD22 in turn recruits SHP1, which may regulate CD19 or its associated kinases by dephosphorylation.

biological properties attributed to CD19. ${ }^{56} \mathrm{We}$ call this process "processive amplification". That CD19 directly amplifies Lyn activation was revealed using in vitro kinase assays with purified Lyn in the presence or absence of recombinant CD19. ${ }^{21}$ Incubation of Lyn with ATP results in Lyn autophosphorylation. However, adding CD19 cytoplasmic domain protein to a Lyn kinase assay dramatically upregulates both CD19 and Lyn phosphorylation. CD19 also upregulates Lyn phosphorylation of exogenous substrate. Results iden- 
tical to those obtained with Lyn are also obtained with Fyn. Therefore, CD19 serves as a substrate for Srcfamily PTKs, but also amplifies Src-family PTK activity.

The region of the CD19 cytoplasmic domain involved in the amplification of Lyn kinase activity was defined using CD19 peptides and CD19 fusion proteins. Although the binding of phosphopeptides from some proteins can activate Src-family PTKs during $\mathrm{SH} 2$ domain interactions, ${ }^{68,69} \mathrm{CD} 19$ peptides containing individual phosphotyrosine residues of CD19 are unable to amplify Lyn activation. However, a CD19-exon 1214 fusion protein amplifies Lyn to the same extent as the entire CD19-exon 7-14 cytoplasmic domain. Fusion proteins representing exon 7-13, exon 7-10 and exon 8-12 proteins are without activity as is a CD19 exon 14 fusion protein containing only CD19- $\mathrm{Y}^{513}$. A fusion protein encoding the $\sim 140$ amino acid long cytoplasmic domain of CD22 is also unable to amplify Lyn kinase activity, despite the presence of six well-conserved tyrosine residues that include phosphorylation and binding sites for Lyn. ${ }^{5,70}$ This suggests that Lyn amplification is unique to a region of CD19 including exons 12-14 rather than just individual phosphopeptide sequences.

Whether the two Lyn binding sites within CD19exons 13 and 14 are essential elements for amplification of Lyn kinase activity was assessed using mutated CD19-exon 12-14 fusion proteins in which $\mathrm{Y}^{482}$ and/or $\mathrm{Y}^{513}$ were substituted with phenylalanine(s). Compared with an intact exon 12-14 fusion protein, these three mutated CD19-exon 12-14 fusion proteins were unable to amplify Lyn activity during in vitro kinase assays. In addition, Lyn autophosphorylation is only enhanced by CD19-GST fusion proteins containing intact $\mathrm{Y}^{482}$ and $\mathrm{Y}^{513}$ residues. Similarly, the simultaneous addition of both CD19-Y $Y^{482}$ and $C D 19-Y^{513}$ peptides or both CD19-GST $\mathrm{Y}^{482} \mathrm{~F}$ and CD19-GST $\mathrm{Y}^{513} \mathrm{~F}$ fusion proteins to in vitro kinase assays does not affect Lyn activity. This establishes that intact $\mathrm{Y}^{482}$ and $\mathrm{Y}^{513}$ residues are both required for Lyn kinase activation by CD19 and that CD19-Y ${ }^{513}$ phosphorylation is required before subsequent $\mathrm{CD} 19-\mathrm{Y}^{482}$ phosphorylation on the same molecule.

Based on the above results, it is most likely that the increase in Lyn enzymatic activity observed in these assays results from enhanced conversion of Lyn to an activated state rather than enhancing the enzymatic activity of previously activated Lyn. Therefore, we propose that two Lyn molecules recruited to phosphorylated $\mathrm{CD} 19-\mathrm{Y}^{482}$ and $\mathrm{CD} 19-\mathrm{Y}^{513}$ residues through their $\mathrm{SH} 2$ domains are thereby brought into close proximity (Fig. 3C). The spatial proximity of the Lyn/CD19/Lyn complex results in transphosphorylation and activation of the Lyn molecules bound to CD19 (Fig. 3D). This explains why the linkage and spatial orientation of both CD19-Y482 and CD19-Y $Y^{513}$ is indispensable for CD19 amplification of Lyn kinase activity.

\section{CD19 binding amplifies Lyn phosphorylation of Vav}

In addition to amplifying Src-family PTK activity, CD19 also facilitates molecular interactions that lead to Vav phosphorylation, which is decreased in CD19deficient $\mathrm{B}$ cells. ${ }^{65}$ Vav binds phosphorylated CD19 tyrosine residues directly via its $\mathrm{SH} 2$ domain. The primary binding site for $\mathrm{Vav}$ is $\mathrm{Y}^{391}$, but Vav also interacts with $\mathrm{Y}^{421}$, and weakly with $\mathrm{Y}^{403}$ and $\mathrm{Y}^{513}$ (Fig. 1). That CD19 provides phosphorylated docking sites for both Src-family PTKs and Vav is important since in vitro kinase assays have demonstrated that Lyn can phosphorylate Vav, and that CD19/Lyn interactions facilitate Vav phosphorylation. ${ }^{21}$ Thus, the formation of Lyn/CD19 complexes is likely to enhance both the binding of Vav to CD19 and Lyn phosphorylation of Vav (Fig. 3E). The abolition of Vav tyrosine phosphorylation in Lyn-deficient mice supports this notion. ${ }^{28}$ Therefore, phosphorylated CD19 provides distinct and specific $\mathrm{SH} 2$-domain recognition regions to which Lyn (and other Src-family PTKs) and Vav bind.

Constitutive CD19 phosphorylation by Lyn facilitates the assembly of Lyn/CD19/Vav ternary complexes that are found in resting splenic $\mathrm{B}$ cells. ${ }^{21}$ Interactions between CD19, Lyn, and Vav increase after BCR crosslinking in parallel with increased CD19 phosphorylation. Thus, Src-family PTK binding to CD19 amplifies kinase activity that facilitates efficient Vav phosphorylation by the activated PTK. Vav may then attract other SH2-domain-containing signaling molecules to the CD19 complex, which leads to downstream activation of MAPK cascades. ${ }^{71-73}$ The regulation of Srcfamily PTK activation and Vav phosphorylation by CD19 thereby provides a potent molecular mechanism for amplifying BCR signals.

\section{CD19/PI 3-kinase complexes}

CD19 also interacts with effector molecules downstream of BCR signaling such as phosphatidylinositol 3-kinase (PI 3-kinase). ${ }^{61,64.65 .74,75}$ The tandem SH2 domains of PI 3-kinase p85 subunit bind CD19 dually phosphorylated at $\mathrm{Y}^{482}$ and $\mathrm{Y}^{513}{ }^{56.61}$ Dual phosphorylation of CD19- $Y^{482}$ and CD19-Y $Y^{513}$ by Lyn through processive phosphorylation thereby provides docking sites for PI 3-kinase. ${ }^{56}$ PI 3-kinase also binds duallyphosphorylated CD19 in cell lines. ${ }^{61-63,75,76}$ The kinetics of Lyn's interactions with CD19 suggest that Lyn phosphorylation and binding to CD19 precedes PI 3-kinase binding (Fig. 3E). Lyn constitutively associates with CD19 at relatively high levels in primary B cells 
and BCR engagement increased Lyn's binding to CD19. PI 3-kinase is constitutively associated with CD19 at detectable levels in unstimulated B cells, but the amount of PI 3-kinase precipitated with CD19 increases more than 10 -fold after BCR cross-linking. The relative timing of Lyn and PI 3-kinase associations with phosphorylated CD19 suggests that Lyn binding takes precedence over PI 3-kinase binding following Lyn's phosphorylation of CD19. Thus, CD19 amplification of Lyn kinase activity may influence subsequent PI 3-kinase binding to $\mathrm{CD} 19$ through $\mathrm{Y}^{482}$ and $\mathrm{Y}^{513}$ phosphorylation sites. Indeed, PI 3-kinase phosphorylation is impaired in CD19-deficient B cells following BCR ligation. ${ }^{21}$

While CD19 may function as an adapter molecule to facilitate PI 3-kinase mobilization to the cell surface, the biological significance of this event is yet to be realized. PI 3-kinase facilitates $\left[\mathrm{Ca}^{++}\right]_{i}$ mobilization and activates the Akt protein kinase pathway. ${ }^{77,78}$ Whether targeted deletion of the gene encoding the p85 $\alpha$ subunit of PI 3-kinase affects $\left[\mathrm{Ca}^{++}\right]_{i}$ mobilization has not been reported, although this genetic deletion results in an Xid-like immunodeficiency in mice. ${ }^{79,80}$ Nonetheless, B cells from CD19-deficient mice generate near-normal $\left[\mathrm{Ca}^{++}\right]_{i}$ responses following $\mathrm{BCR}$ engagement. ${ }^{32,81}$ Wortmannin, a potent PI 3-kinase inhibitor, also has relatively small effects on BCR-induced $\left[\mathrm{Ca}^{++}\right]_{i}$ mobilization in wild type $\mathrm{B}$ cells. ${ }^{57}$ Wortmannin also inhibits $\left[\mathrm{Ca}^{++}\right]_{\mathrm{i}}$ responses generated by $\mathrm{B}$ cells from CD19deficient mice (data not shown). Furthermore, the baseline in vitro activity of immunoprecipitated PI 3 kinase is $\sim 50 \%$ higher in CD19-deficient B cells than in wild type $B$ cells before activation (unpublished observations). Following $B C R$ ligation, the relative increase in PI-3 kinase activity is much lower in CD19-deficient B cells than in wild type B cells, although PI 3-kinase activity remains higher in CD19-deficient $B$ cells compared to wild type B cells. Similarly, CD19 expression is not required for the membrane localization of PI 3-kinase activity since Akt phosphorylation is not remarkably inhibited in CD19-deficient B cells while Wortmannin treatment blocks Akt activation (unpublished observations). Thus, while CD19 expression in a plasmacytoma cell line increases PI 3-kinase activation, ${ }^{57}$ loss of CD19 expression does not block activation of the PI 3-kinase/Akt pathway following BCR ligation in primary $B$ cells.

\section{CD22}

\section{CD22 structure, expression, and function}

CD22 is a $140,000 \mathrm{M}_{\mathrm{r}}$ cell-surface glycoprotein of the Ig superfamily expressed only on B cells. CD22 is expressed in the cytoplasm of pro-B and pre-B cells, and on the cell surface as B cells mature to become $\operatorname{IgD}$ positive. ${ }^{70} \mathrm{CD} 22$ is an adhesion receptor for sialic acid bearing ligands expressed in serum, and on disparate hematopoietic and non-hematopoietic cells. ${ }^{82,83}$ The dominant form of $\mathrm{CD} 22$ has seven Ig domains, of which the two amino-terminal Ig domains mediate ligand binding. Although the biological significance of CD22 as a mediator of intercellular interactions remains unclear, $\mathrm{CD} 22$ has critical roles in intracellular signal transduction. The $\sim 140$ amino acid cytoplasmic domain of CD22 contains six tyrosines that are targets for rapid phosphorylation following surface $\mathrm{Ig}$ or CD22 ligation. ${ }^{84,85}$ These tyrosines are localized within ITAMlike sequences and ITIMs, suggesting positive and negative signaling functions for CD22. ${ }^{19,20}$

Development of CD22-deficient mice has clarified the functions of $\mathrm{CD} 22$ in vivo. ${ }^{16,86-89} \mathrm{~B}$ cells from CD22-deficient mice develop normally, but their numbers are reduced in the periphery. Shorter lifespans and enhanced apoptosis are observed in CD22-deficient mice.$^{87} \mathrm{~B}$ cells from CD22-deficient mice demonstrate decreased surface IgM expression with increased major histocompatibility complex class II antigen expression. This phenotype resembles that of $B$ cells that have been chronically exposed to self-antigens or $B$ cells from mice that overexpress CD19. However, the prominent feature of CD22-deficient B cells is that they generate augmented $\left[\mathrm{Ca}^{++}\right]_{i}$ responses following BCR crosslinking. Therefore, CD22 is also likely to act as a cellsurface response-regulator in $\mathrm{B}$ cells that modulates signaling thresholds.

A negative regulatory role for CD22 has been proposed since phosphorylated CD22 recruits SHP1, a potent phosphotyrosine phosphatase that is proposed to limit BCR signaling. ${ }^{90-94}$ However, CD22 functions are complex since CD22-deficient B cells exhibit impaired proliferative responses to anti-IgM stimulation. Consistent with a positive role for $\mathrm{CD} 22$, overall protein tyrosine phosphorylation is reduced in $B$ cells from CD22-deficient mice after BCR cross-linking. Tyrosine phosphorylation of CD79a/CD79b, PLC- $\gamma 2$, and SHIP (for $\mathrm{SH} 2$ domain-containing inositol polyphosphate $5^{\prime}$-phosphatase) is decreased in CD22-deficient B cells following BCR crosslinking, while Src-family PTKs and Syk are phosphorylated at wild type levels. ${ }^{65}$ Supporting this notion, phosphorylated CD22 is reported to physically interact with positive effector molecules including Syk, PI 3-kinase, PLC- $\gamma 2$, Grb2, and SOS. ${ }^{19,20,93-97}$ Thus, interactions between CD22 and multiple other effector molecules contribute to both positive and negative signaling pathways.

\section{Molecular interactions between CD19 and CD22}

CD19 and CD22 appear to have positive and nega- 
tive regulatory effects on $\mathrm{BCR}$ signaling, respectively. For example, Vav tyrosine phosphorylation is modest and transient after BCR cross-linking in CD19-deficient $B$ cells, yet uniquely augmented after BCR or CD19 ligation in $\mathrm{CD} 22$-deficient $\mathrm{B}$ cells. ${ }^{65}$ Furthermore, $\mathrm{CD} 19$ and $\mathrm{CD} 22$ have counter-regulatory effects on MAPK activation. ${ }^{71}$ However, recent studies have shown that $\mathrm{CD} 19$ and $\mathrm{CD} 22$ reciprocally regulate each other's functions and may thereby regulate BCR signal transduction indirectly. In support of this hypothesis, CD19 expression is required for CD22 phosphorylation after BCR ligation. ${ }^{65}$ Decreased phosphorylation of CD22 in CD19-deficient B cells reduces the amount of CD22 associated with SHP1, thereby reducing the negative regulatory effects of $\mathrm{CD} 22$. By contrast, CD19 tyrosine phosphorylation is constitutively higher in CD22-deficient B cells and is increased significantly after BCR ligation relative to wild type B cells. ${ }^{81}$ Augmented CD19 tyrosine phosphorylation in CD22deficient $B$ cells contrasts markedly with $B C R$ phosphorylation, which is reduced in CD22-deficient $\mathrm{B}$ cells following BCR ligation. ${ }^{65}$ Thus, CD19 is necessary to initiate negative regulation provided by $\mathrm{CD} 22$ expression, while CD19 is also likely to be a major target of the CD22 inhibitory pathway (Fig. 3F).

The generation of CD19/CD22-double deficient mice has provided additional insight into the cross-regulation between CD19 and CD22 on B cell signaling. ${ }^{81}$ Functional studies of CD19/CD22-deficient B cells have revealed that CD19-deficiency is dominant in CD19/ CD22-deficient mice, rather than CD19- and CD22deficiencies having additive effects. BCR-induced tyrosine phosphorylation of total cellular proteins is equally impaired in CD19/CD22-deficient and CD19-deficient $\mathrm{B}$ cells, regardless of CD22 expression. Of significance, Lyn kinase activity is only modestly increased in CD19deficient and CD19/CD22-deficient B cells after BCR ligation. Furthermore, Vav tyrosine phosphorylation following BCR ligation is decreased to a similar extent in CD19/CD22-deficient B cells and CD19-deficient B cells. Mitogen-induced proliferation of CD19/CD22deficient $B$ cells is reduced to levels identical with CD19-deficient B cells. Despite reduced proliferation by CD22-deficient $\mathrm{B}$ cells in response to IgM ligation, the combined loss of CD19 and CD22 does not affect proliferation beyond the effect of CD19 loss alone. Serum Ig levels in CD19/CD22-deficient and CD19deficient mice are identical, as are antibody responses to T-dependent antigen immunization. Spleen B cell numbers in CD19/CD22-deficient mice are reduced as in CD19-deficient mice. As occurs in CD19-deficient mice, B1 cells within the peritoneum of CD19/CD22deficient mice are rare, despite increased $\mathrm{B} 1$ cell numbers in CD22-deficient mice. ${ }^{86.88}$ These studies demonstrate further that CD19 expression is necessary for
CD22 function in most cases.

There are instances where CD19 and CD22 appear to have additive effects. In particular, CD19 and CD22 have overlapping influences on unactivated B cells, principally where a role for CD19 is absent or less pronounced. CD22 expression influences circulating B cell numbers with or without CD19 expression. While CD19 loss results in higher IgM expression by immature B cells and CD22 loss results in lower IgM expression by more mature B cells, CD19/CD22-deficient B cells have high IgM expression early and low IgM expression later during maturation. In addition, $\left[\mathrm{Ca}^{++}\right]_{i}$ responses in CD19/CD22-deficient B cells are increased after BCR ligation as occurs in CD22-deficient B cells, although the magnitude and kinetics of the response mimic what is seen in CD19-deficient B cells. Thus, CD19 and CD22 are likely to interact through unknown pathways in addition to those highlighted in this review. For example, it remains unknown how either molecule influences $\left[\mathrm{Ca}^{++}\right]_{i}$ responses following CD19 or BCR engagement. Nonetheless, the majority of the data suggest that CD19 expression is necessary for most functions of $\mathrm{CD} 22$ following BCR ligation.

\section{Conclusions}

Studies of CD19 have provided novel insights into normal and autoimmune $\mathrm{B}$ cell function. These studies suggest that intrinsic signal transduction thresholds regulated by CD19 are a pivotal element in autoantibody production. The generation of a Src-family PTK amplification loop by CD19 represents a novel mechanism for regulating intracellular signal transduction thresholds in addition to its previously hypothesized role as a specialized adapter protein for recruiting signaling effector molecules to the cell surface. ${ }^{22,44}$ CD19 amplification of Src-family PTK function also provides additional insight into why CD19 supplies potent costimulatory function when co-ligated with the BCR complex. That CD19 is associated with both Lyn and Vav in splenic B cells prior to BCR ligation suggests that CD19/Lyn/Vav complexes are constitutively assembled. Similar to the CD19/Lyn/Vav complex, the $B$ cell antigen receptor is constitutively organized into a preformed transducer complex in the absence of antigen ligation, ${ }^{98}$ as is the $T$ cell antigen receptor complex. ${ }^{99}$ The absence of a constitutive CD19/Lyn/Vav signaling complex potentially explains why $B$ cells from CD19-deficient mice are hypo-responsive to transmembrane signals. Similarly, the augmented formation of CD19/Lyn/Vav complexes in transgenic mice that overexpress CD19 may explain why B cells from these mice are hyper-responsive to transmembrane signals and are phenotypically similar to chronically stimulated B cells. ${ }^{24.32}$ Constitutive CD19/Lyn/Vav complex sig- 
naling may therefore be responsible for the establishment of baseline signaling thresholds in B cells prior to antigen receptor ligation, in addition to accelerating signaling following BCR engagement or other transmembrane signals. Augmented formation of CD19/Lyn/ Vav complexes may also predispose to autoimmunity.

These studies unite the previous concept that CD19, CD21, CD22, Lyn, Vav and SHP1 are involved in the regulation of $\mathrm{B}$ lymphocyte signal transduction thresholds and show that each of these molecules contributes to a CD19-regulated pathway. Undoubtedly each molecule also contributes to other pathways. For example, although synergistic interactions between Lyn and CD19 amplify basal and BCR-induced signal transduction, the phenotype of CD19-deficient mice contrasts with that of Lyn-deficient mice, which are autoimmune. ${ }^{28,29,46,48,100}$ This may result in part from CD19 expression being B cell-restricted, while Lyn is expressed broadly within hematopoietic tissues. Lyndeficiency also leads to exaggerated inflammatory stimuli that may contribute to autoimmunity since Lyn negatively regulates cytokine signaling in macrophages through its ability to phosphorylate inhibitory receptors. ${ }^{5}$ Nonetheless, Lyn and CD19 have both positive and negative roles in BCR-mediated signal transduction. ${ }^{5,15}$ For example, signal termination following activation of the CD22 inhibitory pathway is a critical function for Lyn. ${ }^{28,29,100}$. Lyn is responsible for CD22 phosphorylation, ${ }^{7}$ while CD22 phosphorylation and function is upregulated by $\mathrm{CD} 19$ expression as well. ${ }^{65,81}$ Therefore, we propose that CD19-mediated amplification of the Src-family PTK pathway is required for initiating the down-regulatory functions of CD22. Remarkably, CD19 is a major target for the downregulatory functions of $\mathrm{CD} 22 .{ }^{81}$ Thereby, $\mathrm{CD} 19$ expression synergistically modulates the positive and negative roles of Lyn, although Lyn regulates other pathways as well. Furthermore, CD19 may only modulate the activation of a specialized pool of intracellular Lyn kinase since the majority of intracellular Lyn did not associated with CD19. Whether CD19 and the BCR complex share the same small pool of cellular Lyn is unknown. CD19 may also regulate the activation of other Src-family PTK members since Fyn and Blk tyrosine phosphorylation are diminished in CD19deficient B cells. ${ }^{21}$ Thus, the collective phenotypes of Lyn-deficient and CD19-deficient mice are likely to reflect multiple qualitative and quantitative factors which account for their differences.

The identification of a subset of patients that overexpress CD19 and the demonstration that similar CD19 overexpression in mice leads to the production of autoantibodies suggests that the CD19 signaling pathway contributes to human disease. This also establishes a new paradigm by which very subtle changes in expres- sion or function of tightly regulated signal transduction molecules may predispose to autoimmunity. Since multiple signaling molecules (CD19, CD21, CD22, Lyn, Vav and SHP1) appear to contribute to a common signaling pathway it is possible that subtle alterations in the expression or function of any of these molecules could induce pathology. In a broader sense, any alteration that disrupts the normal balance of signal transduction in resting or activated $B$ cells may also predispose to autoimmunity. ${ }^{9} \mathrm{~A}$ further understanding of how B lymphocyte signaling thresholds are regulated at the molecular level will undoubtedly reveal additional autoimmunity susceptibility genes that function at the cell surface and within the cytoplasm. The further challenge will be to understand how these molecules interact and how combinations of subtle alterations interact to cause the different manifestations of autoimmune disease.

\section{References}

1. Reth $\mathrm{M}$, Wienands $\mathrm{J}$ : Initiation and processing of signals from the B cell antigen receptor. Annu Rev Immunol 1997; 15: 453479

2. DeFranco AL: The complexity of signaling pathways activated by the BCR. Curr Opin Immunol 1997; 9: 296-308

3. Kurosaki $T$ : Genetic analysis of B cell antigen receptor signaling. Annu Rev Immunol 1999; 17: 555-592

4. Tamir I, Cambier JC: Antigen receptor signaling: integration of protein tyrosine kinase functions. Oncogene 1998; 17: 13531364

5. DeFranco AL, Chan VW, Lowell CA: Positive and negative roles of the tyrosine kinase Lyn in B cell function. Semin Immunol 1998; 10: 299-307

6. Saouaf SJ, Mahajan S, Rowley RB, Kut SA, Fargnoli J, Burkhardt AL, Tsukada S, Witte ON, Bolen JB: Temporal differences in the activation of three classes of non-transmembrane protein tyrosine kinases following B-cell antigen receptor surface engagement. Proc Natl Acad Sci USA 1994; 91: 9524-9528

7. Chan VW, Lowell CA, DeFranco AL: Defective negative regulation of antigen receptor signaling in Lyn-deficient B lymphocytes. Curr Biol 1998; 8: 545-553

8. Smith KGC, Tarlinton DM, Doody GM, Hibbs ML, Fearon DT: Inhibition of the B cell by CD22: a requirement for Lyn. J Exp Med 1998; 187: 807-811

9. Cornall RJ, Cyster JG, Hibbs ML, Dunn AR, Otipoby KL, Clark EA, Goodnow CC: Polygenic autoimmune traits: Lyn, $\mathrm{CD} 22$, and SHP-1 are limiting elements of a biochemical pathway regulating BCR signaling and selection. Immunity 1998; 8 : 497-508

10. Nishizumi H, Horikawa K, Mlinaric-Rascan I, Yamamoto T: A double-edged kinase Lyn: a positive and negative regulator for antigen receptor-mediated signals. J Exp Med 1998; 187: 13431348

11. Thomas SM, Brugge JS: Cellular functions regulated by Src family kinases. Annu Rev Cell Dev Biol 1997; 13: 513-609

12. Sicheri F, Kuriyan J: Structures of Src-family tyrosine kinases. Curr Opin Struct Biol 1997; 7: 777-785

13. Pawson T: New impressions of Src and Hck. Nature 1997; 385: 582-585

14. Thomas ML, Brown EJ: Positive and negative regulation of 
Src-family membrane kinases by CD45. Immunol Today 1999 ; 20: 406-411

15. Tedder TF: Introduction: response-regulators of B lymphocyte signaling thresholds provide a context for antigen receptor signal transduction. Semin Immunol 1998; 10: 259-265

16. Sato S, Tuscano JM, Inaoki M, Tedder TF: CD22 negatively and positively regulates signal transduction through the B lymphocyte antigen receptor. Semin Immunol 1998; 10: 287-297

17. Fujimoto $M$, Poe JC, Inaoki M, Tedder TF: CD19 regulates $B$ lymphocyte responses to transmembrane signals. Semin Immunol 1998; 10: 267-277

18. Carter RH, Doody GM, Bolen JB, Fearon DT: Membrane IgM-induced tyrosine phosphorylation of CD19 requires a CD19 domain that mediates association with components of the B cell antigen receptor complex. J Immunol 1997; 158: 3062 3069

19. Leprince C, Draves KE, Geahlen RL, Ledbetter JA, Clark EA: $\mathrm{CD} 22$ associates with the human surface IgM-B cell antigen receptor complex. Proc Natl Acad Sci USA 1993; 90: 3236-3240

20. Peaker CJ, Neuberger MS: Association of CD22 with the B cell antigen receptor. Eur J Immunol 1993; 23: 1358-1363

21. Fujimoto M, Poe JC, Jansen PJ, Sato S, Tedder TF: CD19 amplifies B lymphocyte signal transduction by regulating Srcfamily protein tyrosine kinase activation. J Immunol 1999; 162: 7088-7094

22. Tedder $\mathbf{T F}$, Inaoki $\mathrm{M}$, Sato $\mathrm{S}$ : The $\mathrm{CD} 19-\mathrm{CD} 21$ complex regulates signal transduction thresholds governing humoral immunity and autoimmunity. Immunity 1997; 6: 107-118

23. Goodnow CC: Balancing immunity and tolerance: deleting and tuning lymphocyte repertoires. Proc Natl Acad Sci USA 1996; 93: $2264-2271$

24. Sato S, Ono N, Steeber DA, Pisetsky DS, Tedder TF: CD19 regulates $\mathrm{B}$ lymphocyte signaling thresholds critical for the development of B-1 lineage cells and autoimmunity. J Immunol 1996; $157: 4371-4378$

25. Inaoki M, Sato S, Weintraub BC, Goodnow CC, Tedder TF: CD19-regulated signaling thresholds control peripheral tolerance and autoantibody production in B lymphocytes. J Exp Med 1997; 186: 1923-1931

26. Prodeus AP, Goerg S, Shen LM, Pozdnyakova OO, Chu L, Alicot EM, Goodnow CC, Carroll MC: A critical role for complement in maintenance of self-tolerance. Immunity 1998; 9: $721-731$

27. O'Keefe TL, Williams GT, Batista FD, Neuberger MS: Deficiency in CD22, a B cell-specific inhibitory receptor, is sufficient to predispose to development of high affinity autoantibodies. J Exp Med 1999; 189: 1307-1313

28. Nishizumi H, Taniuchi I, Yamanashi Y, Kitamura D, Ilic D, Mori S, Watanabe T, Yamamoto T: Impaired proliferation of peripheral $B$ cells and indication of autoimmune disease in lyndeficient mice. Immunity 1995; 3: 549-560

29. Hibbs ML, Tarlinton DM, Armes J, Grail D, Hodgson G, Maglitto R, Stacker SA, Dunn AR: Multiple defects in the immune system of Lyn-deficient mice, culminating in autoimmune disease. Cell 1995; 83: 301-311

30. Tsui HW, Siminovitch KA, de Souza L, Tsui FW: Motheaten and viable motheaten mice have mutations in the haematopoietic cell phosphatase gene. Nat Genet 1993; 4: 124-129

31. Okano Y: Antinuclear antibody in systemic sclerosis (scleroderma). Rheum Dis Clin North Am 1996; 22: 709-735

32. Sato S, Steeber DA, Jansen PJ, Tedder TF: CD19 expression levels regulate B lymphocyte development: human CD19 restores normal function in mice lacking endogenous CD19. J Immunol 1997; 158: 4662-4669

33. Krop I, Shaffer AL, Fearon DT, Schlissel MS: The signaling activity of murine CD19 is regulated during cell development. J Immunol 1996; 157: 48-56

34. Boyd AW, Anderson KC, Freedman AS, Fisher DC, Slaughenhoupt B, Schlossman SF, Nadler LM: Studies of in vitro activation and differentiation of human B lymphocytes. I. Phenotypic and functional characterization of the $B$ cell population responding to anti-Ig antibody. J Immunol 1985; 134: 15161523

35. Carroll MC: $\mathrm{CD} 21 / \mathrm{CD} 35$ in B cell activation. Semin Immunol 1998; 10: 279-286

36. Bradbury LE, Kansas GS, Levy S, Evans RL, Tedder TF: The CD19/CD21 signal transducing complex of human B lymphocytes includes the target of antiproliferative antibody- 1 and Leu-13 molecules. J Immunol 1992; 149: 2841-2850

37. Maecker HT, Todd SC, Levy S: The tetraspanin superfamily: molecular facilitators. Faseb J 1997; 11: 428-442

38. Maecker HT, Levy S: Normal lymphocyte development but delayed humoral immune response in CD81-null mice. J Exp Med 1997; 185: 1505-1510

39. Miyazaki T, Muller U, Campbell KS: Normal development but differentially altered proliferative responses of lymphocytes in mice lacking CD81. Embo J 1997; 16: 4217-4225

40. Tsitsikov EN, Gutierrez-Ramos JC, Geha RS: Impaired CD19 expression and signaling enhanced antibody response to type II $T$ independent antigen and reduction of $B-1$ cells in CD81deficient mice. Proc Natl Acad Sci USA 1997; 94: 10844-10849

41. Deblandre GA, Marinx OP, Evans SS, Majjaj S, Leo O, Caput D, Huez GA, Wathelet MG: Expression cloning of an interferon-inducible $17-\mathrm{kDa}$ membrane protein implicated in the control of cell growth. J Biol Chem 1995; 270: 23860-23866

42. Bradbury LE, Goldmacher VS, Tedder TF: The CD19 signal transduction complex of B lymphocytes: deletion of the CD19 cytoplasmic domain alters signal transduction but not complex formation with TAPA-1 and Leu-13. J Immunol 1993; 151: 2915-2927

43. Matsumoto AK, Martin DR, Carter RH, Klickstein LB, Ahearn JM, Fearon DT: Functional dissection of the CD21/ CD19/TAPA-1/Leu-13 complex of B lymphocytes. J Exp Med 1993; 178: 1407-1417

44. Fearon DT, Carter RH: The CD19/CR2/TAPA-1 complex of B lymphocytes: linking natural to acquired immunity. Annu Rev Immunol 1995; 13: 127-149

45. van Noesel CJ, Lankester AC, van Lier RA: Dual antigen recognition by B cells. Immunol Today 1993; 14: 8-11

46. Engel P, Zhou LJ, Ord DC, Sato S, Koller B, Tedder TF: Abnormal B lymphocyte development, activation, and differentiation in mice that lack or overexpress the CD19 signal transduction molecule. Immunity 1995; 3: 39-50

47. Zhou LJ, Smith HM, Waldschmidt TJ, Schwarting R, Daley J, Tedder TF: Tissue-specific expression of the human CD19 gene in transgenic mice inhibits antigen-independent B lymphocyte development. Mol Cell Biol 1994; 14: 3884-3894

48. Rickert RC, Rajewsky K, Roes J: Impairment of T-celldependent B-cell responses and B-1 cell development in CD19deficient mice. Nature $1995 ; 376$ : 352-355

49. Sato S, Steeber DA, Tedder TF: The CD19 signal transduction molecule is a response regulator of B-lymphocyte differentiation. Proc Natl Acad Sci USA 1995; 92: 11558-11562

50. Sato S, Miller AS, Howard MC, Tedder TF: Regulation of B lymphocyte development and activation by the CD19/CD21/ CD81/Leu 13 complex requires the cytoplasmic domain of CD19. J Immunol 1997; 159: 3278-3287

51. Tedder TF, Isaacs CM: Isolation of cDNAs encoding the CD19 antigen of human and mouse B lymphocytes. A new member of the immunoglobulin superfamily. J Immunol 1989; 143: 712-717 
52. van Noesel CJ, Lankester AC, van Schijndel GM, van Lier RA: The CR2/CD19 complex on human B cells contains the srcfamily kinase Lyn. Int Immunol 1993; 5: 699-705

53. Uckun FM, Burkhardt AL, Jarvis L, Jun X, Stealey B, Dibirdik I, Myers DE, Tuel-Ahlgren L, Bolen JB: Signal transduction through the CD19 receptor during discrete developmental stages of human B-cell ontogeny. J Biol Chem 1993; 268: 21172-21184

54. Chalupny NJ, Kanner SB, Schieven GL, Wee SF, Gilliland LK, Aruffo A, Ledbetter JA: Tyrosine phosphorylation of CD19 in pre-B and mature B cells. Embo J 1993; 12: 2691-2696

55. Bireland ML, Monroe JG: Biochemistry of antigen receptor signaling in mature and developing B lymphocytes. Crit Rev Immunol 1997; 17: 353-385

56. Fujimoto M, Fujimoto $\mathrm{Y}$, Poe JC, Jansen PJ, Lowell CA, DeFranco AL, Tedder TF: CD19 is a specialized transmembrane adapter protein that amplifies Src-family protein tyrosine kinase activation. (submitted):

57. Buhl AM, Pleiman CM, Rickert RC, Cambier JC: Qualitative regulation of $\mathrm{B}$ cell antigen receptor signaling by CD19: Selective requirement for PI 3-kinase activation, inositol-1,4,5trisphosphate production and $\mathrm{Ca}^{2+}$ mobilization. J Exp Med 1997; 186: 1897-1910

58. Li HL, Forman MS, Kurosaki T, Pure E: Syk is required for BCR-mediated activation of p90Rsk, but not p70S6k, via a mitogen-activated protein kinase-independent pathway in $\mathrm{B}$ cells. J Biol Chem 1997; 272: 18200-18208

59. El-Hillal O, Kurosaki T, Yamamura H, Kinet JP, Scharenberg AM: syk kinase activation by a src kinase-initiated activation loop phosphorylation chain reaction. Proc Natl Acad Sci USA 1997; 94: 1919-1924

60. Buhl AM, Cambier JC: Phosphorylation of CD19 Y484 and Y515, and linked activaiton of phosphatidylinositol 3-kinase, are required for $B$ cell antigen receptor-mediated activation of Bruton's tyrosine kinase. J Immunol 1999; 162: 4438-4446

61. Tuveson DA, Carter RH, Soltoff SP, Fearon DT: CD19 of B cells as a surrogate kinase insert region to bind phosphatidylinositol 3-kinase. Science 1993; 260: 986-989

62. Weng WK, Jarvis L, LeBien TW: Signaling through CD19 activates Vav/mitogen-activated protein kinase pathway and induces formation of a CD19/Vav/phosphatidylinositol 3-kinase complex in human B cell precursors. J Biol Chem 1994; 269: 32514-32521

63. Li X, Sandoval D, Freeberg L, Carter RH: Role of CD19 tyrosine 391 in synergistic activation of B lymphocytes by coligation of CD19 and membrane Ig. J Immunol 1997; 158: 5649-5657

64. O'Rourke LM, Tooze R, Turner M, Sandoval DM, Carter RH, Tybulewicz VL, Fearon DT: CD19 as a membrane-anchored adaptor protein of B lymphocytes: costimulation of lipid and protein kinases by recruitment of Vav. Immunity 1998; 8: 635645

65. Sato S, Jansen PJ, Tedder TF: CD19 and CD22 expression reciprocally regulates tyrosine phosphorylation of Vav protein during B lymphocyte signaling. Proc Natl Acad Sci USA 1997; 94: $13158-13162$

66. Zhou LJ, Ord DC, Hughes AL, Tedder TF: Structure and domain organization of the CD19 antigen of human, mouse and guinea pig B lymphocytes. Conservation of the extensive cytoplasmic domain. J Immunol 1991; 147: 1424-1432

67. Zhou S, Cantley LC: Recognition and specificity in protein tyrosine kinase-mediated signalling. Trends Biochem Sci 1995 20: $470-475$

68. Clark MR, Johnson SA, Cambier JC: Analysis of Ig-alphatyrosine kinase interaction reveals two levels of binding specificity and tyrosine phosphorylated Ig-alpha stimulation of Fyn activity. Embo J 1994; 13: 1911-1919

69. Ruzzene M, Brunati AM, Donella-Deana A, Marin O, Pinna LA: Specific stimulation of c-Fgr kinase by tyrosinephosphorylated (poly)peptides: possible implication in the sequential mode of protein phosphorylation. Eur J Biochem 1997; 245: 701-707

70. Tedder TF, Tuscano J, Sato S, Kehrl JH: CD22, a B lymphocyte-specific adhesion molecule that regulates antigen receptor signaling. Annu Rev Immunol 1997; 15: 481-504

71. Tooze RM, Doody GM, Fearon DT: Counterregulation by the coreceptors CD19 and CD22 of MAP kinase activation by membrane immunoglobulin. Immunity $1997 ; 7: 59-67$

72. Weng WK, Shah N, O'Brien D, Van Ness B, LeBien TW: Differential induction of DNA-binding activities following CD19 cross-linking in human B lineage cells. J Immunol 1997; 159: 5502-5508

73. Li X, Carter RH: Convergence of CD19 and B cell antigen receptor signals at MEK1 in the ERK2 activation cascade. J Immunol 1998; 161: 5901-5908

74. Lankester AC, van Schijndel GM, Rood PM, Verhoeven AJ, van Lier RA: B cell antigen receptor cross-linking induced tyrosine phosphorylation and membrane translocation of a multimeric Shc complex that is augmented by CD19 co-ligation. Eur J Immunol 1994; 24: 2818-2825

75. Beckwith $\mathrm{M}$, Jorgensen $\mathrm{G}$, Longo DL: The protein product of the proto-oncogene c-cbl forms a complex with phosphatidylinositol 3-kinase p85 and CD19 in anti-IgM-stimulated human B-lymphoma cells. Blood 1996; 88: 3502-3507

76. Chalupny NJ, Aruffo A, Esselstyn JM, Chan PY, Bajorath J, Blake J, Gilliland LK, Ledbetter JA, Tepper MA: Specific binding of Fyn and phosphatidylinositol 3-kinase to the B cell surface glycoprotein CD19 through their src homology 2 domains. Eur J Immunol 1995; 25: 2978-2984

77. Marte BM, Downward J: PKB/Akt: connecting phosphoinositide 3-kinase to cell survival and beyond. Trends Biochem Sci 1997; 22: 355-358

78. Franke TF, Kaplan DR, Cantley LC: PI3K: downstream AKTion blocks apoptosis. Cell 1997; 88: 435-437

79. Suzuki H, Terauchi Y, Fujiwara M, Aizawa S, Yazaki Y, Kadowaki T, Koyasu S: Xid-like immunodeficiency in mice with disruption of the p85 $\alpha$ subunit of phosphoinositide 3-kinase. Science 1999; 283: 390-392

80. Fruman DA, Snapper SB, Yballe CM, Davidson L, Yu JY, Alt FW, Cantley LC: Impaired B cell development and proliferation in absence of phosphoinositide 3-kinase p85a. Science 1999; 283: 393-397

81. Fujimoto M, Bradney AP, Poe JC, Steeber DA, Tedder TF: Modulation of $\mathrm{B}$ lymphocyte antigen receptor signal transduction by a CD19/CD22 regulatory loop. Immunity 1999; 11: 191-200

82. Engel P, Nojima Y, Rothstein D, Zhou LJ, Wilson GL, Kehrl JH, Tedder TF: The same epitope on CD22 of B lymphocytes mediates the adhesion of erythrocytes, $\mathrm{T}$ and $\mathrm{B}$ lymphocytes, neutrophils and monocytes. J Immunol 1993; 150: 4719-4732

83. Kelm S, Pelz A, Schauer R, Filbin MT, Tang S, de Bellard ME, Schnaar RL, Mahoney JA, Hartnell A, Bradfield P, Crocker PR: Sialoadhesin, myelin-associated glycoprotein and CD22 define a new family of sialic acid-dependent adhesion molecules of the immunoglobulin superfamily. Curr Biol 1994; 4: 965-972

84. Schulte RJ, Campbell MA, Fischer WH, Sefton BM: Tyrosine phosphorylation of CD22 during B cell activation. Science 1992; 258: $1001-1004$

85. Wilson GL, Fox CH, Fauci AS, Kehrl JH: cDNA cloning of the $B$ cell membrane protein CD22: a mediator of B-B cell interactions. J Exp Med 1991; 173: 137-146 
86. Sato S, Miller AS, Inaoki M, Bock CB, Jansen PJ, Tang ML, Tedder TF: CD22 is both a positive and negative regulator of $B$ lymphocyte antigen receptor signal transduction: altered signaling in CD22-deficient mice. Immunity 1996; 5: 551-562

87. Otipoby KL, Andersson KB, Draves KE, Klaus SJ, Farr AG, Kerner JD, Perlmutter RM, Law CL, Clark EA: CD22 regulates thymus-independent responses and the lifespan of $B$ cells. Nature 1996; 384: 634-637

88. O'Keefe TL, Williams GT, Davies SL, Neuberger MS: Hyperresponsive B cells in CD22-deficient mice. Science 1996; 274: 798-801

89. Nitschke L, Carsetti R, Ocker B, Kohler G, Lamers MC: CD22 is a negative regulator of $\mathrm{B}$-cell receptor signalling. Curr Biol 1997; 7: 133-143

90. Doody GM, Justement LB, Delibrias CC, Mathews RJ, Lin J, Thomas ML, Fearon DT: A role in B cell activation for CD22 and the protein tyrosine phosphatase SHP. Science 1995; 269: 242-244

91. Lankester AC, van Schijndel GM, van Lier RA: Hematopoietic cell phosphatase is recruited to CD22 following $B$ cell antigen receptor ligation. J Biol Chem 1995; 270: 20305-20308

92. Campbell MA, Klinman NR: Phosphotyrosine-dependent association between $\mathrm{CD} 22$ and protein tyrosine phosphatase 1C. Eur J Immunol 1995; 25: 1573-1579

93. Law CL, Sidorenko SP, Chandran KA, Zhao Z, Shen SH, Fischer EH, Clark EA: CD22 associates with protein tyrosine phosphatase $1 \mathrm{C}$, Syk, and phospholipase C- $\gamma 1$ upon B cell acti- vation. J Exp Med 1996; 183: 547-560

94. Blasioli J, Paust S, Thomas ML: Definition of the sites of interaction between the protein tyrosine phosphatase SHP-1 and CD22. J Biol Chem 1999; 274: 2303-2307

95. Yohannan J, Wienands J, Coggeshall KM, Justement LB: Analysis of tyrosine phosphorylation-dependent interactions between stimulatory effector proteins and the B cell co-receptor CD22. J Biol Chem 1999; 274: 18769-18776

96. Tuscano J, Engel P, Tedder TF, Kehrl JH: Engagement of the adhesion receptor $\mathrm{CD} 22$ triggers a potent stimulatory signal for $B$ cells and blocking CD22/CD22L interactions impairs T-cell proliferation. Blood 1996; 87: 4723-4730

97. Tuscano JM, Engel P, Tedder TF, Agarwal A, Kehrl JH: Involvement of p72syk kinase, p53/56lyn kinase and phosphatidyl inositol-3 kinase in signal transduction via the human B lymphocyte antigen CD22. Eur J Immunol 1996; 26: 1246-1252

98. Wienands J, Larbolette $\mathrm{O}$, Reth $\mathrm{M}$ : Evidence for a preformed transducer complex organized by the $B$ cell antigen receptor. Proc Natl Acad Sci USA 1996; 93: 7865-7870

99. van Oers NS, Killeen N, Weiss A: ZAP-70 is constitutively associated with tyrosine-phosphorylated TCR $\zeta$ in murine thymocytes and lymph node $T$ cells. Immunity 1994; $1: 675-685$

100. Chan VW, Meng F, Soriano P, DeFranco AL, Lowell CA: Characterization of the B lymphocyte populations in Lyndeficient mice and the role of Lyn in signal initiation and downregulation. Immunity 1997; 7: 69-81 